\title{
An Alternate Form of the Integrated First-Order Rate Equation
}

\section{ISSN: 2637-8078}

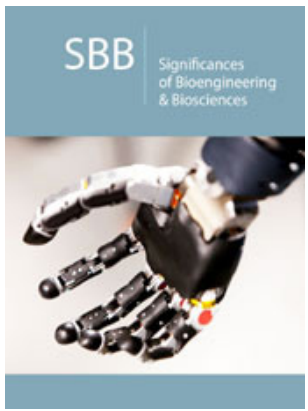

*Corresponding author: Frank E Stary, Department of Chemistry, USA

Submission: 侮 June 11, 2019

Published: 侮June 25, 2019

Volume 3 - Issue 3

How to cite this article: Frank E Stary. An Alternate Form of the Integrated First-Order Rate Equation.Significances Bioeng Biosci.3(3). SBB.000564.2019.

DOI: 10.31031/SBB.2019.03.000564

Copyright@ Frank E Stary, This article is distributed under the terms of the Creative Commons Attribution 4.0 International License, which permits unrestricted use and redistribution provided that the original author and source are credited.

\section{Frank E Stary* \\ Department of Chemistry, USA}

\section{Abstract}

Derivation of a first-order equation suitable for use in beginning energy science and chemistry courses is shown to be

$A=A_{o} / 2^{t / t_{1 / 2}}$

Where,

Ao is the original amount of the sample

$A$ is the amount

$\mathrm{T}$ is time $\mathrm{t}$ and

$\mathrm{t} 1 / 2$ is the half-life

Ao is larger than A

\section{Derivation of the Alternate Form}

Radioactive processes and many chemical processes follow first order kinetics. The usual equations

found in general chemistry textbooks are:

a. $\ln A o / A=k t$, Where, $\mathrm{A}_{\mathrm{o}}$ is the original amount of the sample, $\mathrm{A}$ is the amount at time $\mathrm{t}$ and $\mathrm{k}$ is the rate constant.

b. Changing the rate constant to half-life, $\ln 2=k t_{12}$, where $t_{1 / 2}$ is the half-life.

c. Solving equation 2 for $\mathrm{k}$ and substituting into equation 1 the result is $\ln A o / A=(\ln 2) t / t_{1 / 2}$.

d. Rearranging equation 3 gives $A=A_{o} / e^{(\ln 2) t / t_{1 / 2}}$ as indicated in [1].

e. Since $e^{\ln 2}=2$, substitution into equation 4 yields $A=A_{o} / 2^{t / t_{12}}$ the Alternate Form of the

\section{Integrated first-order rate equation}

Our students have found equation 5 to be relatively easier to use than equations 1 and 2 . In equation 5 , by dividing the time by the half-life, they get a number. On their calculators, they enter the number $2, \mathrm{y}^{\mathrm{x}}$, the number and press=The result is divided into $\mathrm{A}_{\mathrm{o}}$, giving the value for A. For radioactive processes, the values of Ao and A may be in mass, such as grams, or activity in Becquerel's (counts/second). For chemical processes, units for $\mathrm{A}_{\mathrm{o}}$ and A may be written as rates, such as molarity/second.

\section{References}

1. Kenneth AC (1991) Chemical kinetics, the study of reaction rates in solution. VCH Publishers, USA, p. 496.

For possible submissions Click below: 